\title{
Production and characterization of activated carbon from barley straw by physical activation with carbon dioxide and steam
}

\author{
Javier Pallarés*, Ana González-Cencerrado, Inmaculada Arauzo
}

Universidad de Zaragoza- IUI mixto CIRCE

Campus Río Ebro, Mariano Esquillor Gómez, 15, 50018 Zaragoza, Spain

*Corresponding Author Email: jpallare@unizar.es

\section{Highlights}

- Activated carbons derived from barley present a well-developed microporosity

- $\mathrm{CO}_{2}$ activation develops a higher microporous structure than steam activation

- Temperature and heating rate are the most relevant factors during carbonization

- Temperature and hold time are the most relevant factors during activation

- Activation produce an increase in the aromaticity and dehydrogenation of the chars

\section{Keywords}

Activated carbon, biochar, barley straw, physical activation

\begin{abstract}
In recent years, the growth of environmental protection policies has generated an increase in the global demand for activated carbon, the most widely used adsorbent in many industrial sectors, and with good prospects of implemetation in others such as energy storage (electrodes in supercapacitors) and agriculture (fertilizer production). This demand is driving by the search for renewable, abundant and low-cost precursor materials, as an alternative to traditional fossil sources. This study investigates the production of activated carbon from barley straw using physical activation method with two different activating agents, carbon dioxide and steam. Experimental tests under different conditions at each stage of the process, carbonization and activation, have been conducted in order to maximize the BET surface area and microporosity of the final product. During the carbonization stage, temperature and heating rate have been found to be the most relevant factors, while activation temperature and hold time played this role during activation. Optimal conditions for the activation stage were obtained at $800{ }^{\circ} \mathrm{C}$ and a hold time of 1 hour in the case of activation with carbon dioxide and at $700{ }^{\circ} \mathrm{C}$ and a hold time of 1 hour in the case of activation with steam. The maximum BET surface area and micropore volume achieved by carbon dioxide activation were of $789 \mathrm{~m}^{2} / \mathrm{g}$ and $0.3268 \mathrm{~cm}^{3} / \mathrm{g}$ while for steam activation were $552 \mathrm{~m}^{2} / \mathrm{g}$ and $0.2304 \mathrm{~cm}^{3} / \mathrm{g}$, which represent respectively an increase of more than $43 \%$ and $42 \%$ for the case of activation with carbon dioxide.
\end{abstract}




\section{Introduction}

Adsorption in solids is one of the best available techniques for the purification of water and the control of atmospheric and aquatic pollution, with activated carbon being the most widely used adsorbent in industry. In the last decade, global consumption of activated carbon has grown by an average annual increase of $5.5 \%$ and it is forecasted to continue to do so at an even higher rate in the coming years (8.1\% in 2018 [1]).

The increase in the demand for activated carbon has been associated with its traditional uses in the treatment and purification of water and polluting gases, especially in the most industrialized regions of the world, where more restrictive environmental regulations have been imposed. In Asian countries, led by China and India, this demand growth has been even greater due to the rapid industrial development and high population growth, the implementation and improvement of drinking water treatment systems, the increase in ownership rates of motor vehicles, the intensification of agriculture and the increase of environmental regulations to manufacturing industries.

On the other hand, activated carbon demand has also increased as a result of new applications, amongst which stands out the interest aroused in the use of these adsorbents in mitigation of mercury emissions from coal thermal power plants. Another application of activated carbon attracting interest today is its use as an adsorbent in post-combustion systems for the reduction and capture of $\mathrm{CO}_{2}$ emissions [2,3]. Moreover, the use of activated carbon electrodes in supercapacitors taking advantage of its microporous structure to reduce the electrode's electrical resistance and improve energy storage performance is growing, promoted by the great interest in developing a new generation of batteries that definitely boost the electric car [3, 4]. Finally, there are numerous studies that demonstrate the positive effect that the activated carbon has on the fertility of agricultural soils, with the consequent increase in crop yields [5]. Its use as an amendment can achieve important benefits on the reduction of $\mathrm{N}_{2} \mathrm{O}, \mathrm{NH}_{3}$ and nitrogen leachates $[6,7]$.

Activated carbon is an adsorbent obtained from carbonaceous materials with a disorganized crystallographic structure, constituted by randomly distributed microcrystals. This microcrystalline structure is built from elementary structures such as graphene sheets and fullerene or quasi-graphitic fragments. However, this microcrystalline arrangement does not extend on a macroscopic scale resulting in a disordered and highly nanoporous structure. Consequently, these materials present a high specific surface area (500-1500 $\left.\mathrm{m}^{2} / \mathrm{g}\right)$, a wide variety of functional groups (carboxylates, carbonyls, hydroxyls, amines) and a pore size 
distribution ( $<1-100 \mathrm{~nm})$. All these characteristics give them an extraordinary capacity to adsorb a great diversity of molecules [8].

The characteristics of activated carbon as an adsorbent, both in capacity and in selectivity towards the species to be adsorbed, depend on the degree of disorganization of the microcrystalline structure, which is conditioned by both the nature of the precursor material and the process to which it has been subjected for transformation into activated carbon. This is because the resulting porosity can vary both in shape and in dimensions, with pores ranging from less than $1 \mathrm{~nm}$ to more than $1000 \mathrm{~nm}$. The final application of a determined activated carbon will depend mainly on its porosity and on the chemical properties of its surface.

There are basically two processes for the production of activated carbons: physical activation and chemical activation. The most common activated carbon production process is physical activation. This process takes place in two stages. During the first stage, called carbonization, the precursor material is pyrolyzed, in an inert atmosphere at a medium-high temperature (300$800^{\circ} \mathrm{C}$ ). During this process, the breaking of the less stable bonds releases the volatile fraction of the precursor material, which is formed by permanent gases and tars, and a carbonaceous residue enriched in carbon aromatic rings is obtained, the so-called char, which has a rudimentary porous structure. This initial porosity has a low adsorption capacity, since part of the products released during the decomposition, mostly tars, re-polymerize and condense on the surface of the particle, filling or blocking the pores. That is why a subsequent activation stage is required, through which these tar deposits will be eliminated, thus enlarging the existing porosity and increasing the adsorption capacity.

During the second stage, char is activated at a higher temperature $\left(700-1000{ }^{\circ} \mathrm{C}\right)$ in the presence of an activating agent. Throughout this process, the carbonaceous matrix of the fuel, exposed to a reducing atmosphere, undergoes several heterogeneous reforming reactions leading to a partial gasification of the char, developing a large porous structure and increasing its specific surface area. During the initial stage of the activation process, the following processes take place: elimination of the tar deposits, opening of rudimentary pores formed during pyrolysis and development of new pores. After a long activation period, pore-widening becomes the dominant effect while pore deepening and new pore formation are severely reduced. Consequently, more meso and macropores are evolved and BET surface area and pore volume decrease with increasing activation time [9].

Carbon dioxide and steam are the most widespread activating agents because the endothermic nature of their reactions facilitates process control. Generally, the use of carbon dioxide is 
preferred due to its lower reactivity at high temperature, which makes the activation process easier to control. In addition, from the initial stages of activation, carbon dioxide activation favors microporosity formation, whereas steam activation favors microporosity widening, and thus activated carbons prepared with steam exhibit a lower micropore volume at the expense of larger meso and macropore volumes [10]. In any case, the most determinant factors in the development of the microporous structure are the gasifying agent's partial pressure and the conditions of the activation process, and thus, both $\mathrm{CO}_{2}$ and steam can be suitable gasifying agents depending on the choice of precursor material and process conditions [11-13].

Activated carbon can also be produced by a chemical activation process. In this case the precursor is impregnated with activating chemical agents such as $\mathrm{KOH}, \mathrm{H}_{3} \mathrm{PO}_{4}$ or $\mathrm{ZnCl}_{2}$. Subsequently, the precursor is subjected to a carbonization process at moderate temperatures $\left(550{ }^{\circ} \mathrm{C}\right.$ ) and, finally, the resulting activated carbon is washed to remove activator traces which might remain in the material and to recover the chemical agent for successive generation cycles of activated carbon. However, at an industrial scale, physical activation is preferred because it allows for the optimization of the pyrolysis stage by enabling a greater control over microporosity development and eliminates the requirement for chemicals, reducing both the process' costs and associated pollution.

The production of activated carbon has traditionally been obtained from wood, coal, petroleum residues, lignite and polymers, all of which are very expensive and, with the exception of wood, non-renewable. Consequently, in the search for renewable and cost-competitive alternatives, scientific interest in the production of activated carbon from byproducts and biomass residues (so-called activated biochar) has grown in recent years [14-16]. The main advantage of activated carbon derived from alternative sources, compared to traditional activated carbon, lies in its high availability and low cost. In addition, tests performed with these alternative activated carbon materials in various applications (e.g. water purification, elimination of polluting gases, mercury removal or control-release fertilizers) have presented at least an equivalent behavior, than commercial activated carbon or other much more expensive alternatives, such as carbon nanotubes and graphene [3].

On the experimental field, since 2000, numerous studies have been conducted using a diverse range of precursor materials of residual biomass origin (corn, rapeseed, barley, almond shells, walnut, pistachio, peanut, acorn, rice, palm, olive pomace, cherry bones, date bones, bamboo, cotton stalks, miscanthus, sicyos, ...), being currently a field of study in growing expansion. With regards to the physical activation process, most published studies focus on the preparation of activated carbons from residual biomass sources, optimizing the conditions of the activation 
process with carbon dioxide or steam and the subsequent physical and chemical characterization [11-13,17-26]. Other studies, in a much smaller number, have analyzed the influence of the carbonization process conditions in the subsequent activation stage [27-30]. Finally, for specific applications such as the adsorption of heavy metals, where it is important to increase the content of certain carboxyl, hydroxyl and amino functional groups that can be combined with the metals by ion exchange, complexation or electrostatic attraction, studies have focused on the maximization of these groups. In the case of adsorption of pollutants of organic origin, studies have aimed at increasing the hydrophobicity and polarity of activated biochar [3]. In general, all the studies have concluded that using as precursors material of biomass origin can either match or improve the properties of commercial activated carbon obtained from traditional sources.

Within this context, the specific objective of this study is to investigate the capacity of barley straw as a biomass precursor material for the production of activated carbon under different operating conditions and activating agents via the physical activation process. Barley, besides being one of the main products contributing to the world diet, and the crop with greater territorial base and distribution in Spain, presents adequate characteristics for the production of activated carbon. In the literature there are no published studies on obtaining activated carbon from barley straw by the physical route (Loredo-Cancino et al. published a study on chemical activation of barley husks in 2013 [31]), which adds a special interest since this study extends the knowledge in the search for new, viable and low cost precursors. To this purpose, using an externally heated quartz reactor, the effect of final temperature, heating rate, hold time and gas flow rate of both $\mathrm{CO}_{2}$ and steam in the production of activated carbon from barley straw have been investigated. Samples of the resulting activated carbon have been physically and chemically characterized for analysis and discussion.

\section{Materials and Methodology}

\subsection{Preparation and characterization of the precursor material}

In this study, barley straw has been used as a precursor material for the production of activated carbon. Besides its favorable characteristics for the production of activated carbon, barley is the main crop in Spain where an average 6 million hectares of cereals are cultivated annually. This represents $12 \%$ of the country's geographical area and $44 \%$ of its total cultivated area. In the 2016/17 season, it was estimated that $42.8 \%$ of the production corresponds to barley [32].

Morphologically, barley is composed of a cane shaped trunk and grain producing spikes. Barley's seeds are used extensively for both human and animal feeding, making it one of the main contributors to the world's food consumption. 
After the removal of grains for food production and other possible secondary uses of some of the residual biomass (e.g. cattle feeding, livestock beds and energy production), 15-50\% of the waste straw remains unused. Only in Spain, considering the values of barley production and a residue/crop product ratio of 1.2 [33], this equates to 2-6 Mt annually.

During the harvest of the cereal, the straw is spread in the field, where it is collected and mechanically packed. Then, for its use in the production of activated carbon, other typical pretreatments, such as drying and grinding, are necessary. Therefore, the barley straw used in the tests was dried in a drying oven at $105{ }^{\circ} \mathrm{C}$ until its moisture stabilized below $10 \%$. Size reduction by grinding and subsequent classification were carried out in a hammer mill coupled to a vibrating sieve-classifier, establishing a classification size range between 0.045 and 0.5 $\mathrm{mm}$. Table 1 presents the mass fractions retained in each of the sieves according to the UNECEN/TS 15149-2 EX standard.

\begin{tabular}{|c|c|c|}
\hline Particle size (mm) & Mass Fraction (\% mass) & Cumulative undersize (\% mass) \\
\hline$<0.045$ & 3.26 & 3.26 \\
\hline 0.045 & 2.21 & 5.47 \\
\hline 0.075 & 8.42 & 13.89 \\
\hline 0.1 & 6.00 & 19.89 \\
\hline 0.15 & 13.82 & 33.71 \\
\hline 0.25 & 36.56 & 70.27 \\
\hline 0.355 & 22.17 & 92.43 \\
\hline 0.5 & 6.98 & 99.41 \\
\hline
\end{tabular}

Table 1. Particle size distribution

Table 2 and Table 3 present respectively the proximate, ultimate and ash composition analysis of the studied biomass. It can be observed that barley presents a low ash and a high volatile content, similar to other biomass residual materials that have already been reported in literature for the production of activated carbon by the physical activation process such as almond shells [17], pistachio shells [24] and maize corncob [19]. Finally, ash composition analysis (Table 3) shows a high presence of $\mathrm{Si}$ and $\mathrm{K}$, while other major elements are $\mathrm{Ca}, \mathrm{Mg}, \mathrm{P}$ and $\mathrm{S}$ with concentrations higher than 1\%. From an agronomic point of view, the ash presents a great variety of macro (P, K, S, Ca and Mg) and micro nutrients (Fe, Mn, Zn) which adds value for its potential use in agriculture. 


\begin{tabular}{|l|l|c|}
\hline Moisture & UNE EN 14774-2 & 9.0 \\
\hline Volatiles & UNE EN 15148 & 77.2 \\
\hline Fixed Carbon & by difference & 17.3 \\
\hline Ash & UNE EN 14775 & 5 \\
\hline $\mathbf{C}$ & UNE EN 15104 & 45.4 \\
\hline $\mathbf{H}$ & UNE EN 15104 & 6.1 \\
\hline $\mathbf{O}$ & by difference & 41.92 \\
\hline $\mathbf{N}$ & UNE EN 15104 & 0.7 \\
\hline $\mathbf{S}$ & UNE EN 15289 & 0.07 \\
\hline $\mathbf{C l}$ & UNE EN 15289 & 0.31 \\
\hline
\end{tabular}

Table 2. Proximate and ultimate analysis (\% wt. dry basis)

\begin{tabular}{|c|c|c|c|}
\hline Element & \% wt & Element & \% wt \\
\hline $\mathbf{A l}$ & 0.82 & $\mathbf{N a}$ & 0.50 \\
\hline $\mathbf{B a}$ & 0.021 & $\mathbf{P}$ & 1.3 \\
\hline $\mathbf{C a}$ & 7.2 & $\mathbf{S}$ & 1.1 \\
\hline $\mathbf{F e}$ & 0.42 & $\mathbf{S i}$ & 21 \\
\hline $\mathbf{K}$ & 18.0 & $\mathbf{S r}$ & 0.022 \\
\hline $\mathbf{M g}$ & 2.0 & $\mathbf{T i}$ & 0.046 \\
\hline $\mathbf{M n}$ & 0.054 & $\mathbf{Z n}$ & 0.019 \\
\hline
\end{tabular}

Table 3. Major and minor elements in ash at $550{ }^{\circ} \mathrm{C}$ (\% wt. dry basis) (UNE EN 15290)

\subsection{Experimental facility}

The production of activated carbon was carried out through a physical activation process in two stages: carbonization with nitrogen and activation with carbon dioxide or steam in an externally heated quartz tubular reactor.

Figure 1 shows the layout of the experimental rig where the tests have been conducted. The main part of the rig is a horizontal, resistance-heated tubular furnace (Nabertherm $\mathrm{R}$ 170/1000/12), inside of which a cylindrical quartz reactor of $1730 \mathrm{~mm}$ long and $162 \mathrm{~mm}$ internal diameter is located. The installation is completed by a gas inlet line which has three independent valves to allow for process gas flow rate regulation of nitrogen, carbon dioxide, both coming from compressed gas cylinders, and steam, produced with a steam generator at 150 ${ }^{\circ} \mathrm{C}$. Additionally, a condenser is installed in the gas exit line, which allows for cooling down 
and separation of the water and tars formed during the process. After the condenser, the gases pass through a coalescing filter where any humidity and remaining tar mist are retained. Pressure and temperature measurements in both lines, flow rate meters and a gas chromatograph (Varian 490-GC PRO) to determine the composition of the exhaust gases are also available.

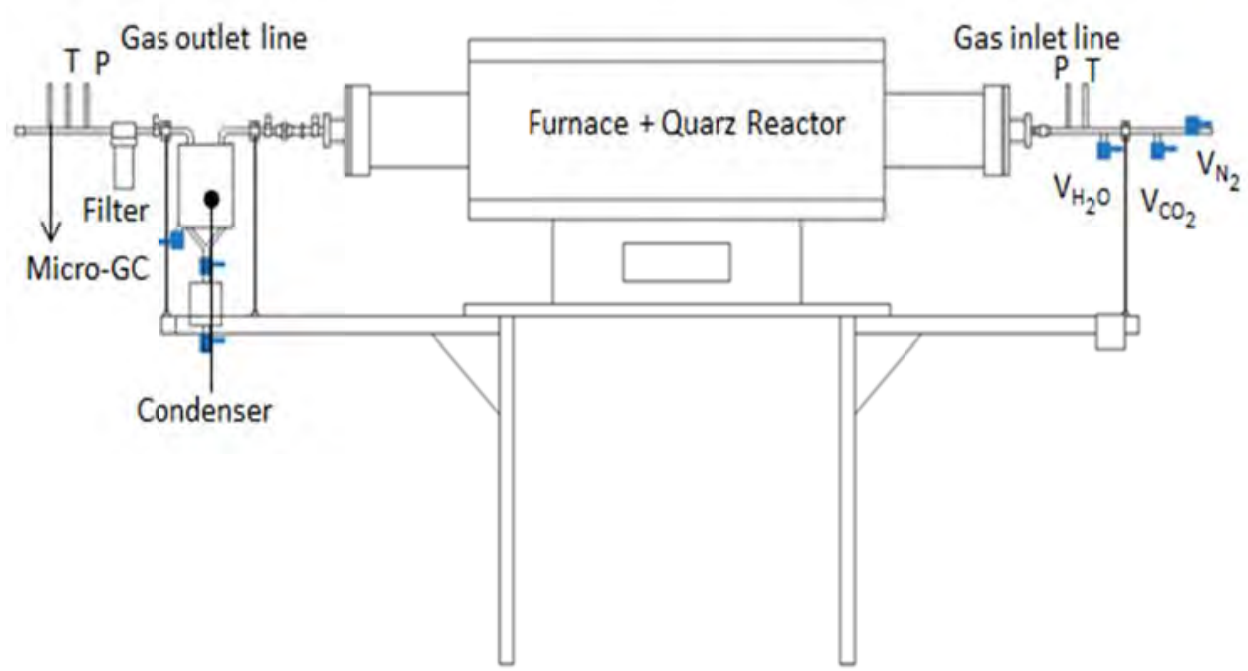

Figure 1. Layout of the externally heated quartz tubular reactor facility.

\subsection{Experimental test campaign and procedure}

The development of the activated carbon's microstructure is strongly dependent on the conditions in which carbonization and activation take place, i.e. final temperature, heating rate, holding time and gas mass flow rate. Consequently, the experimental campaign has focused on analyzing the influence of the different operating variables in each stage of the process in order to maximize the BET surface area and microporosity of the final product. Table 4 shows the conditions in which the tests have been carried out: gas flow rate, temperature (T), heating rate $(\beta)$, and hold time (t). Initially, the influence of the variables in the pyrolysis process was analyzed (tests 1 to 6), keeping the conditions for activation with $\mathrm{CO}_{2}$ constant. Then, building on from the optimized conditions for pyrolysis, experiments were designed to evaluate the influence of the conditions on steam and $\mathrm{CO}_{2}$ activation.

The general experimental procedure followed for running the tests is detailed below. Firstly, approximately $25 \mathrm{~g}$ of precursor material were prepared on a quartz sample vessel, previously dried and ground as indicated in section 2.1. Secondly, in order to eliminate any remaining moisture and avoid condensation during experimentation, the samples were kept for 24 hours in a drying oven at $105{ }^{\circ} \mathrm{C}$ prior to being introduced in the reactor. Thirdly, after introducing the sample into the reactor but before heating, a flow of nitrogen from the compressed gas cylinder 
was passed through the installation to eliminate the presence of oxygen and create the inert conditions required for complete pyrolysis. Then complete pyrolysis and activation were undertaken according to the test conditions defined in Table 4. Finally, once the activation temperature was reached, nitrogen flow was switched to the corresponding activating agent. Once the program was completed, the installation was cooled down in an inert nitrogen atmosphere.

\begin{tabular}{|c|c|c|c|c|c|c|c|c|c|}
\cline { 2 - 10 } \multicolumn{1}{c|}{} & \multicolumn{4}{c|}{ Carbonization } & \multicolumn{5}{c|}{ Activation } \\
\hline $\mathbf{T e s t}$ & $\begin{array}{c}\mathbf{N}_{\mathbf{2}} \\
\left(\mathbf{c m}^{\mathbf{3} / \mathbf{m i n})}\right.\end{array}$ & $\mathbf{T}\left({ }^{\circ} \mathbf{C}\right)$ & $\begin{array}{c}\boldsymbol{\beta} \\
\left({ }^{\circ} \mathbf{C} / \mathbf{m i n}\right)\end{array}$ & $\mathbf{t}(\mathbf{h})$ & $\mathbf{G a s}$ & $\left(\mathbf{c m}^{3} / \mathbf{m i n}\right)$ & $\begin{array}{c}\mathbf{T} \\
\left({ }^{\circ} \mathbf{C}\right)\end{array}$ & $\begin{array}{c}\boldsymbol{\beta} \\
\left({ }^{\circ} \mathbf{C} / \mathbf{m i n}\right)\end{array}$ & $\mathbf{t}(\mathbf{h})$ \\
\hline $\mathbf{1}$ & 2500 & 500 & 10 & 1 & $\mathrm{CO}_{2}$ & 2500 & 800 & 10 & 1 \\
\hline $\mathbf{2}$ & 2500 & 600 & 10 & 1 & $\mathrm{CO}_{2}$ & 2500 & 800 & 10 & 1 \\
\hline $\mathbf{3}$ & 2500 & 500 & 5 & 1 & $\mathrm{CO}_{2}$ & 2500 & 800 & 5 & 1 \\
\hline $\mathbf{4}$ & 2500 & 500 & 10 & 2 & $\mathrm{CO}_{2}$ & 2500 & 800 & 10 & 1 \\
\hline $\mathbf{5}$ & 500 & 500 & 10 & 1 & $\mathrm{CO}_{2}$ & 2500 & 800 & 10 & 1 \\
\hline $\mathbf{6}$ & 2500 & 500 & 10 & 1 & $\mathrm{CO}_{2}$ & 4000 & 700 & 10 & 1 \\
\hline $\mathbf{7}$ & 2500 & 500 & 10 & 1 & $\mathrm{CO}_{2}$ & 4000 & 900 & 10 & 1 \\
\hline $\mathbf{8}$ & 2500 & 500 & 10 & 1 & $\mathrm{CO}_{2}$ & 4000 & 800 & 10 & 2 \\
\hline $\mathbf{9}$ & 2500 & 500 & 10 & 1 & $\mathrm{H}_{2} \mathrm{O}$ & 4000 & 600 & 10 & 1 \\
\hline $\mathbf{1 0}$ & 2500 & 500 & 10 & 1 & $\mathrm{H}_{2} \mathrm{O}$ & 4000 & 700 & 10 & 1 \\
\hline $\mathbf{1 1}$ & 2500 & 500 & 10 & 1 & $\mathrm{H}_{2} \mathrm{O}$ & 4000 & 800 & 10 & 1 \\
\hline $\mathbf{1 2}$ & 2500 & 500 & 10 & 1 & $\mathrm{H}_{2} \mathrm{O}$ & 2500 & 700 & 10 & 1 \\
\hline
\end{tabular}

Table 4. Operation conditions during activation tests

\subsection{Characterization techniques of activated carbon}

In order to determine the BET surface area, total volume porosity and microporosity of each activated carbon developed during the physical activation process, $\mathrm{N}_{2}$ adsorption isotherm at 77 K was determined by gas sorption analyzer ASAP 2020 (Micromeritics). Adsorption data were obtained over the relative pressure, $P / P_{0}$, ranging from $10^{-3}$ to 0.99 . The samples were degassed in a vacuum at $200{ }^{\circ} \mathrm{C}$ for 5 hours. Surface area, $S_{\mathrm{BET}}$, was calculated using the BET (Brunauer, Emmett and Teller) equation. The total pore volume was estimated to be equal to the liquid volume of adsorbate $\left(\mathrm{N}_{2}\right)$ at a relative pressure of 0.99 , assuming a cross-sectional area of a nitrogen molecule of $0.162 \mathrm{~nm}^{2}$. Micropore surface area and volume were calculated using the 
t-plot method and pore size distributions were obtained by applying the DFT (Density Functional Theory) method.

In order to determine the surface functional groups on activated carbon, which is useful to define the interactions between the adsorbate and adsorbent and thus the selectivity for adsorption of specific pollutants, the chemical characterization was carried out by ATR-FTIR spectroscopy. The infrared transmission spectra were recorded with a Bruker Vertex 70 spectrometer in the range $500-4000 \mathrm{~cm}^{-1}$ with a resolution of $4 \mathrm{~cm}^{-1}$.

The aforementioned analyses were complemented determining the weight loss due to activation, the ultimate analysis (CHNS Thermo Flash 1112 analyzer), induced coupled-plasma optical emission spectroscopy (ICP-OES Thermo Elemental IRIS Intrepid) to determine the elements present in the sample, and SEM/EDX microscopy (JEOL JSM 6400) to examine the surface morphology and element composition of samples.

\section{Results and discussion}

\section{1. $\mathbf{N}_{2}$ adsorption isotherms and physical properties}

Adsorption capacity is one of the most important properties of activated carbons. Results of weight loss and physical properties of the final activated carbons are then presented. Table 5 shows the initial mass of the sample $\left(\mathrm{M}_{\mathrm{o}}\right)$, final mass $\left(\mathrm{M}_{\mathrm{f}}\right)$, weight loss, BET surface area $\left(\mathrm{S}_{\mathrm{BET}}\right)$, micropore surface area $\left(\mathrm{S}_{\text {micro }}\right)$, total pore volume $\left(\mathrm{V}_{\mathrm{T}}\right)$, micropore volume $\left(\mathrm{V}_{\text {micro }}\right)$ and desorption average pore diameter (D).

The results obtained show a weight loss greater than $70 \%$ for all the cases, and in most of the tests, a very high level of microporosity development after the physical activation process, with a BET surface area close to $800 \mathrm{~m}^{2} / \mathrm{g}$ in the cases of activation with carbon dioxide and above $500 \mathrm{~m}^{2} / \mathrm{g}$ in the cases of activation with steam. These results either match or improve those obtained with different precursors materials from other residual biomass sources under the physical activation process (e.g. El-Hendawy et al. 2001 [19], Girgis et al. 2002 [20], Fan et al. 2004 [21], Zhang et al. 2004 [22], Aworn et al. 2008 [12], Okutucu et al. 2011 [24], Demiral et al. 2011 [25], Rambabu et al. 2015 [13]) and are also comparable to those achieved in the study by Loredo-Cancino et al. 2013 [31] with barley under chemical activation process, which typically produces greater BET surface area $\left(811 \mathrm{~m}^{2} / \mathrm{g}\right.$ compared to $788 \mathrm{~m}^{2} / \mathrm{g}$ obtained in this work).

The increase in the BET surface area is due to the appearance of micropores, evidenced by the increase in adsorption at low relative pressures $\left(\mathrm{p} / \mathrm{p}_{0}<0.1\right)$, as shown in the adsorption- 
desorption nitrogen isotherms in Figure 2. All the adsorption isotherms are of type I according to the IUPAC classification [34], which is characteristic of microporous structures where the total amount adsorbed is reached at relative pressures $\mathrm{p} / \mathrm{p}_{0}$ close to unity. Exceptions are cases 7 and 9, where the present microporosity is very low and also very narrow $(<1 \mathrm{~nm})$. This meant that the nitrogen had difficulty diffusing during testing and, consequently, the points of the isotherm in the adsorption curve as in the desorption curve were not in equilibrium. Therefore, the desorption isotherm was not closed over the adsorption isotherm, making it impossible to carry out any analysis of pore size distribution and calls into question the reliability of the BET surface area measurement. For this reason they have not been included in Table 5.

\begin{tabular}{|c|c|c|c|c|c|c|c|c|}
\hline Test & $M_{0}(g)$ & $\mathbf{M}_{\mathrm{f}}(\mathrm{g})$ & $\begin{array}{l}\text { Weight } \\
\text { loss (\%) }\end{array}$ & $\begin{array}{c}S_{\text {BET }} \\
\left(\mathrm{m}^{2} / \mathrm{g}\right)\end{array}$ & $\begin{array}{l}S_{\text {micro }} \\
\left(\mathrm{m}^{2} / \mathrm{g}\right)\end{array}$ & $\begin{array}{c}V_{T} \\
\left(\mathrm{~cm}^{3} / \mathrm{g}\right)\end{array}$ & $\begin{array}{l}V_{\text {micro }} \\
\left(\mathrm{cm}^{3} / \mathrm{g}\right)\end{array}$ & $D(\mathrm{~nm})$ \\
\hline 1 & 25.141 & 3.486 & 86.14 & 789 & 778 & 0.3495 & 0.3268 & 1.773 \\
\hline 2 & 25.802 & 3.454 & 86.62 & 704 & 693 & 0.3199 & 0.2936 & 1.819 \\
\hline 3 & 24.903 & 3.178 & 87.24 & 718 & 705 & 0.3268 & 0.2986 & 1.822 \\
\hline 4 & 25.007 & 3.529 & 85.89 & 769 & 766 & 0.3438 & 0.3252 & 1.789 \\
\hline 5 & 25.046 & 3.806 & 84.81 & 759 & 748 & 0.3434 & 0.3175 & 1.810 \\
\hline 6 & 25.006 & 7.465 & 70.14 & 211 & 209 & 0.0938 & 0.0830 & 1.778 \\
\hline 7 & 25.013 & 1.150 & 95.40 & - & - & - & - & - \\
\hline 8 & 25.164 & 1.956 & 92.23 & 160 & 154 & 0.0849 & 0.0657 & 2.121 \\
\hline 9 & 26.329 & 7.504 & 71.50 & - & - & - & - & - \\
\hline 10 & 26.217 & 6.122 & 76.65 & 552 & 540 & 0.2576 & 0.2304 & 1.867 \\
\hline 11 & 26.160 & 2.582 & 90.13 & 534 & 500 & 0.2994 & 0.2186 & 2.235 \\
\hline 12 & 27.517 & 6.544 & 76.22 & 530 & 519 & 0.2440 & 0.2210 & 1.843 \\
\hline
\end{tabular}

Table 5. Physical properties of activated carbon 


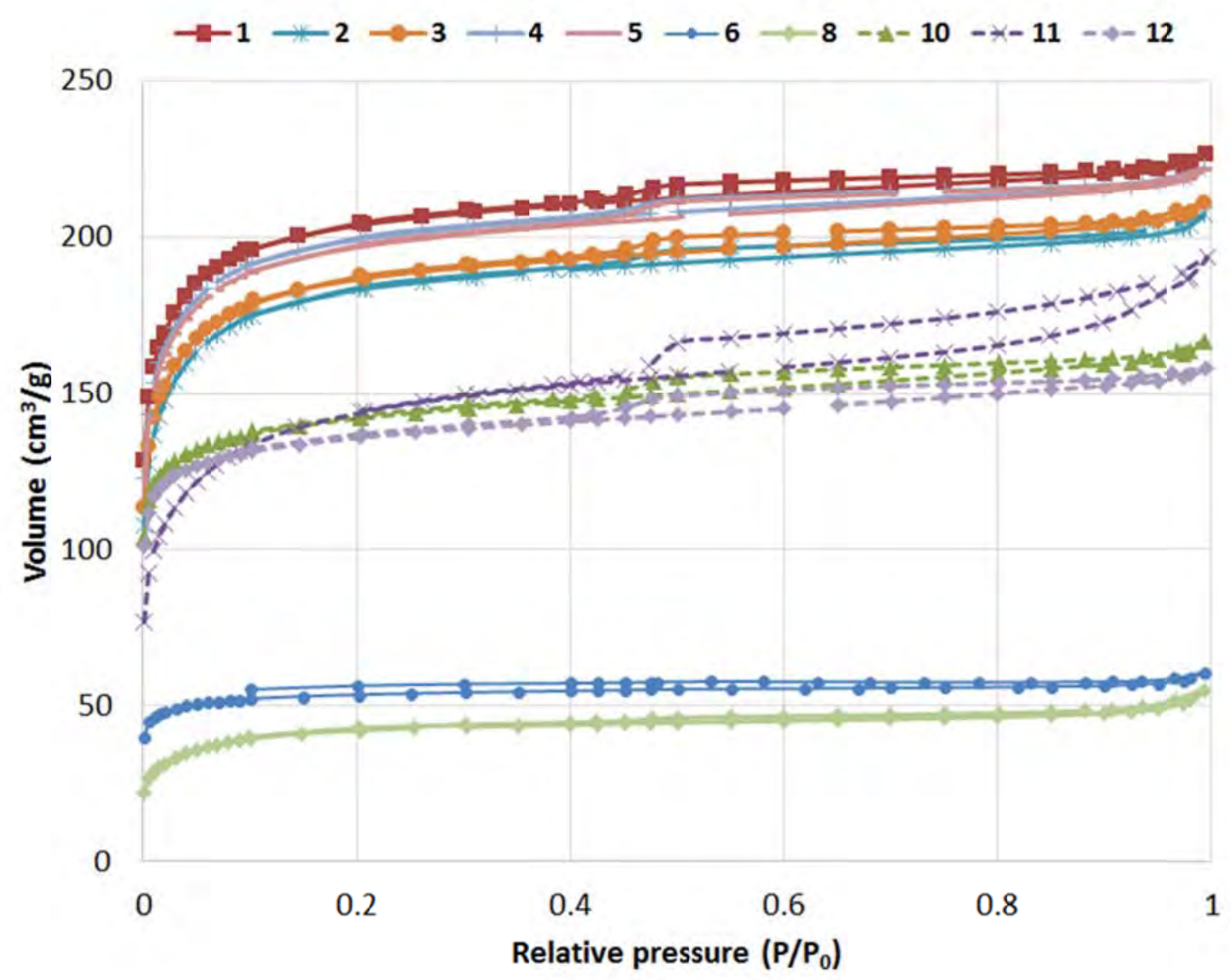

Figure 2. Adsorption-desorption isotherms of $\mathrm{N}_{2}$ of activated carbon

\subsubsection{Carbonization}

The first point of discussion focuses on the conditions of the carbonization process (cases 1 to 5). It was found that increasing the temperature of pyrolysis from $500{ }^{\circ} \mathrm{C}$ to $600{ }^{\circ} \mathrm{C}$ resulted in a decrease of BET surface area (from 789 to $704 \mathrm{~m}^{2} / \mathrm{g}$ ), total volume (from 0.3495 to 0.3199 $\mathrm{cm}^{3} / \mathrm{g}$ ) and micro pore volume (from 0.3268 to $0.2936 \mathrm{~cm}^{3} / \mathrm{g}$ ) of the resultant activated carbon. In general, an increase of the pyrolysis temperature leads to a greater release of volatile matter, resulting in an increase of the initial porous structure that will be further developed during the activation stage. However, when pyrolysis temperature is too high, softening and sintering of the high molecular weight volatiles takes place and results in the depolymerization and shrinkage of the particles, which in turns produces a decrease in the micropone surface area and volume [29]. On the other extreme, pyrolysis temperatures below $500{ }^{\circ} \mathrm{C}$ do not allow the complete devolatilization of the low molecular weight volatiles, and consequently hinder the development of a rudimentary initial porosity.

Increasing heating rate, $\beta$, from $5{ }^{\circ} \mathrm{C} / \mathrm{min}$ to $10^{\circ} \mathrm{C} / \mathrm{min}$ results in an increase of the BET surface area (from 718 to $789 \mathrm{~m}^{2} / \mathrm{g}$ ) and in the total (from 0.3268 to $0.3495 \mathrm{~cm}^{3} / \mathrm{g}$ ) and micro pore 
volume (from 0.2986 to $0.3268 \mathrm{~cm}^{3} / \mathrm{g}$ ), as a result of increase pore development during the pyrolysis stage. This result has been confirmed by many studies in the literature [28-30], which also point out that for heating rates over $10{ }^{\circ} \mathrm{C} / \mathrm{min}$ this tendency is reversed because of partial graphitization with the formation of graphene structures inside the particle and the appearance of both melting and sintering processes on the surface.

Regarding to the hold time, a longer stage can lead to the formation of a molten intermediate phase on the surface of the particle which blocks the existing pores and limits the formation of new ones. Under the conditions analyzed, there was a slight decrease in the development of the BET surface area (from 789 to $769 \mathrm{~m}^{2} / \mathrm{g}$ ) and micropore volume (from 0.3268 to $0.3252 \mathrm{~cm}^{3} / \mathrm{g}$ ) as the pyrolysis hold time increased from 1 to 2 hours. Therefore, it has not been considered as a relevant factor in the process under the conditions analyzed.

It was also observed that a small increase of the gas flow rate facilitates the transportation of released volatiles, preventing both re-polymerization and condensation in the particle's surface of those of higher molecular weight. On the other hand, for externally heated furnaces such as the one used in this study, a large increase in the gas flow rate leads to a decrease of gas temperature and thus sample surface temperature. Consequently, there is a critical gas flow rate value above which the reaction rates are lowered and so less volatile compounds are released, leading to low levels of porosity in the activated carbon [29, 30]. Under the conditions considered in this study, a reduction of the nitrogen gas flow rate from $2500 \mathrm{~cm}^{3} / \mathrm{min}$ to 500 $\mathrm{cm}^{3} / \mathrm{min}$, led to a small decrease in the BET surface area (from 788 to $759 \mathrm{~m}^{2} / \mathrm{g}$ ) and the developed microporosity (from 0.3268 to $0.3175 \mathrm{~cm}^{3} / \mathrm{g}$, showing not to be a relevant factor in the process when compared to others, such as final temperature or heating rate.

The nitrogen adsorption isotherms corresponding to this analysis (cases 1 to 5), have an analogous behavior to each other (Figure 2), displaced on the ordinate axis as a function of the adsorption capacity. In all cases similar slopes can be observed together with the presence of a small hysteresis loop near the relative pressure of 0.45 due to the end of desorption from mesopores. Isotherms are reversible and have a very gentle slope in the multilayer region indicating a low external surface area and the absence of significant mesoporosity.

\subsubsection{Activation}

To find out the influence of the activating agent, the tests performed in cases 1 to 5 using carbon dioxide as activating agent have been completed with other activation tests using carbon dioxide (cases 6 to 8) and steam (cases 9 to 12). In general, this study found that $\mathrm{CO}_{2}$ activation leads to a higher BET surface area and micropore volume than steam activation. The maximum BET 
surface area reached by carbon dioxide activation was $789 \mathrm{~m}^{2} / \mathrm{g}$ while by steam activation was $552 \mathrm{~m}^{2} / \mathrm{g}$. This means, under optimized conditions, an increase of the BET surface area of more than $43 \%$ for the case of activation with carbon dioxide. Total pore and micropore volume also increased when using carbon dioxide as activating agent. An increment of $36 \%\left(0.3495 \mathrm{~cm}^{3} / \mathrm{g}\right.$ by $\mathrm{CO}_{2}$ vs $0.2576 \mathrm{~cm}^{3} / \mathrm{g}$ by $\left.\mathrm{H}_{2} \mathrm{O}\right)$ for pore volume and $42 \%\left(0.3268 \mathrm{~cm}^{3} / \mathrm{g}\right.$ by $\mathrm{CO}_{2}$ vs 0.2304 $\mathrm{cm}^{3} / \mathrm{g}$ by $\mathrm{H}_{2} \mathrm{O}$ ) for micropore volume have been registered in the tests. This result suggested, as it was later confirmed by the analysis of the pore size distribution, that for the case of steam activation the decrease of the microporosity was accompanied by an increase in the mesoporosity of the activated samples $[9,10]$. These results are consistent with other research publications, in which physical activation processes with carbon dioxide and steam were analyzed for several agricultural residues [12,22].

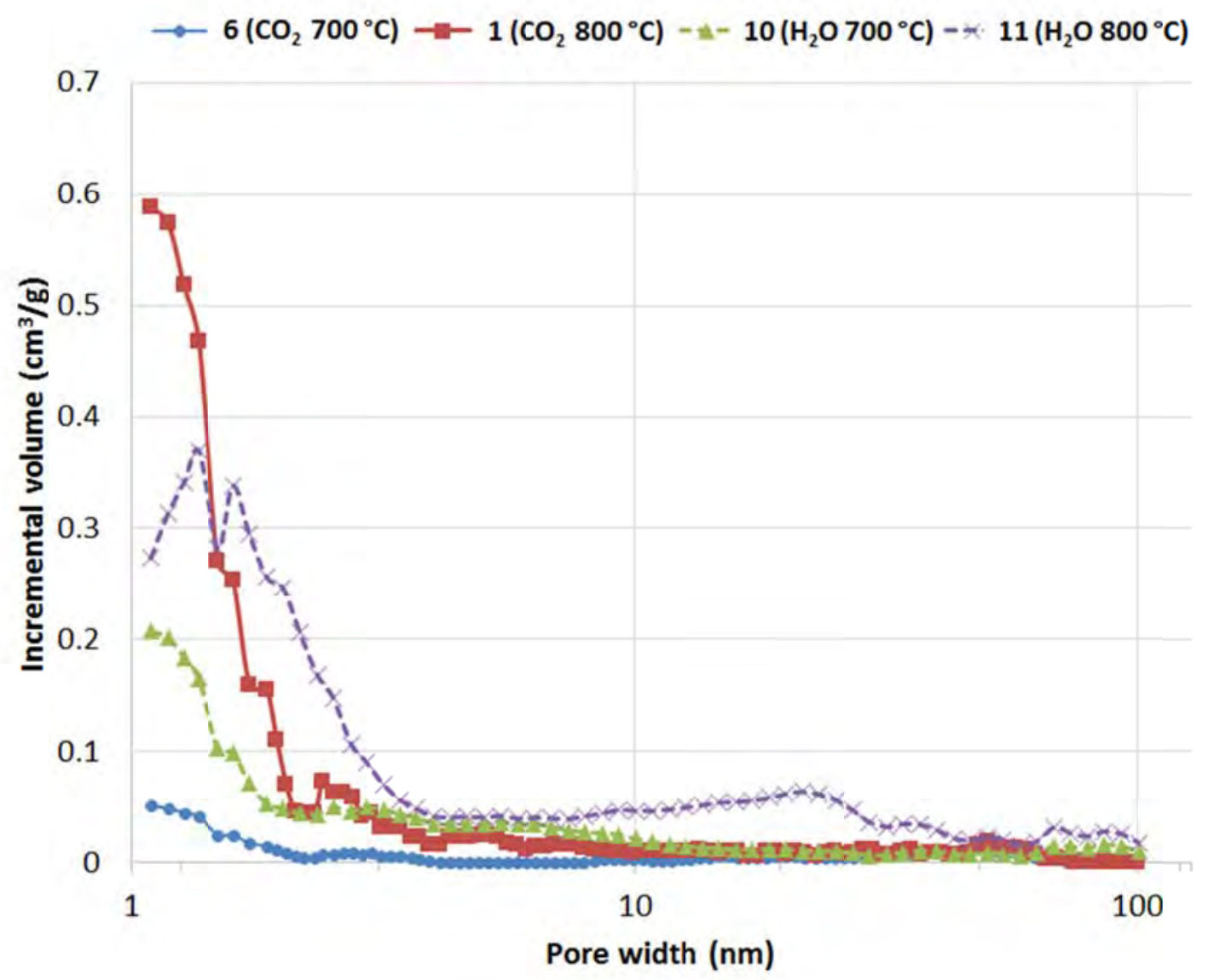

Figure 3. Micropore and mesopore size distribution of activated carbons (temperature)

The adsorption isotherms in Figure 2 show a slightly higher slope and a much more marked hysteresis loop (H4 type) at relative pressures of 0.45 in the cases of steam activation (dashed line) than in the cases of activation with carbon dioxide (solid line), indicating both characteristics an increase in the mesoporosity of the materials. This result is confirmed in 
Figure 3 by comparing the pore size distribution for cases 1 and 11, which correspond respectively to the activation tests with carbon dioxide and steam at $800{ }^{\circ} \mathrm{C}$. It can be observed that for the case of activation with carbon dioxide, the porosity of the sample is concentrated in the region corresponding to micropores with pore sizes less than $2 \mathrm{~nm}$, indicating practically the absence of mesopores and macropores in the material. In the case of steam activation, the microporosity of the sample is also predominant but with a lower degree of development than that of the carbon dioxide activation. Moreover, a non-negligible increase of the adsorption in the region corresponding to mesoporosity is also observed (2 to $50 \mathrm{~nm}$ ); behavior which does not appear for the case of activation with carbon dioxide. These findings are explained by the fact that steam presents a higher reactivity at higher temperatures and gives rise to a pore width enlargement after the initial stage of the activation process that causes a shift from micro to mesoporosity, while the carbon dioxide continues to develop microporosity during this stage.

Next, the influence of the different variables in the activation process is analyzed. In relation to the activation temperature, the maximum BET surface area, total pore volume and microporosity were reached at a temperature of $800{ }^{\circ} \mathrm{C}$ using carbon dioxide, and $700{ }^{\circ} \mathrm{C}$ using steam. This result is consistent with the greater reactivity of water vapor in the heterogeneous steam reforming (water-gas reaction) than carbon dioxide in the so-called Bouduard reaction.

$\mathrm{C}(\mathrm{s})+\mathrm{CO}_{2}(\mathrm{~g}) \rightarrow 2 \mathrm{CO}(\mathrm{g}) \Delta \mathrm{H}_{\mathrm{r}}^{0}=+173 \mathrm{~kJ} / \mathrm{kmol}$

$\mathrm{C}(\mathrm{s})+\mathrm{H}_{2} \mathrm{O}(\mathrm{g}) \rightarrow \mathrm{CO}(\mathrm{g})+\mathrm{H}_{2}(\mathrm{~g}) \quad \Delta \mathrm{H}_{\mathrm{r}}^{0}=+131 \mathrm{~kJ} / \mathrm{kmol}$

In addition, an analysis of the effect of activation temperature for each of the activating agents, showed that, in the case of carbon dioxide, the BET surface area and the total volume of pores and micropores increased remarkably with temperature from 700 to $800{ }^{\circ} \mathrm{C}(274 \%, 273 \%$ and 294\% respectively in cases 6 and 1). Furthermore, the adsorption isotherms (Figure 2) for these two conditions did not show a significant variation in the slope or in the magnitude of the hysteresis loop, suggesting that at $700{ }^{\circ} \mathrm{C}$ the development of new micropores during the activation stage is lower than at $800^{\circ} \mathrm{C}$. This result is confirmed by the pore size distribution presented in Figure 3, where the decrease in microporosity does not correspond to an increase in the mesoporosity of the material. It has also been observed that if the activation temperature is increased up to $900{ }^{\circ} \mathrm{C}$, the final material lacks a porous structure (case 7 in Table 3). On the one hand, the significant increase of the reactivity of the gasification reaction with temperature can enlarge the micropores width causing their collapse. On the other hand, the high content on alkaline metals ( $\mathrm{Na}, \mathrm{K}$ ), alkaline earth metals (Ca, Mg), as well as $\mathrm{Si}, \mathrm{Cl}, \mathrm{S}, \mathrm{P}, \mathrm{Fe}$ of the biomass precursor may interact forming low melting temperature silicates, appearing therefore a melting 
phase which fills and blocks the existing pores. In the case of steam activation, there is also an increase in the development of the microporous structure with temperature from $600{ }^{\circ} \mathrm{C}$ to 700 ${ }^{\circ} \mathrm{C}$. At $600{ }^{\circ} \mathrm{C}$ (case 9 in Table 3) no porosity appears in the final material since, for the 1 hour hold time considered in the test, the elimination of the tar deposits and the opening of the carbonized porosity which forms new micropores has not been completed. On the other hand, when temperature increased from 700 to $800{ }^{\circ} \mathrm{C}$ (cases 10 and 11 respectively), despite a decrease in the BET surface area $(-3 \%)$ and in the micropore volume $(-5.4 \%)$, an overall increase in the total pore volume (9.6\%) was obtained due to the widening of the mesopores. In consequence, in Figure 3 it is observed that, since the activation reactions occur mainly on the outer surface of the particles, the decrease in porosity also occurs in the region of the mesopores, whose widening causes a transition to macropores.

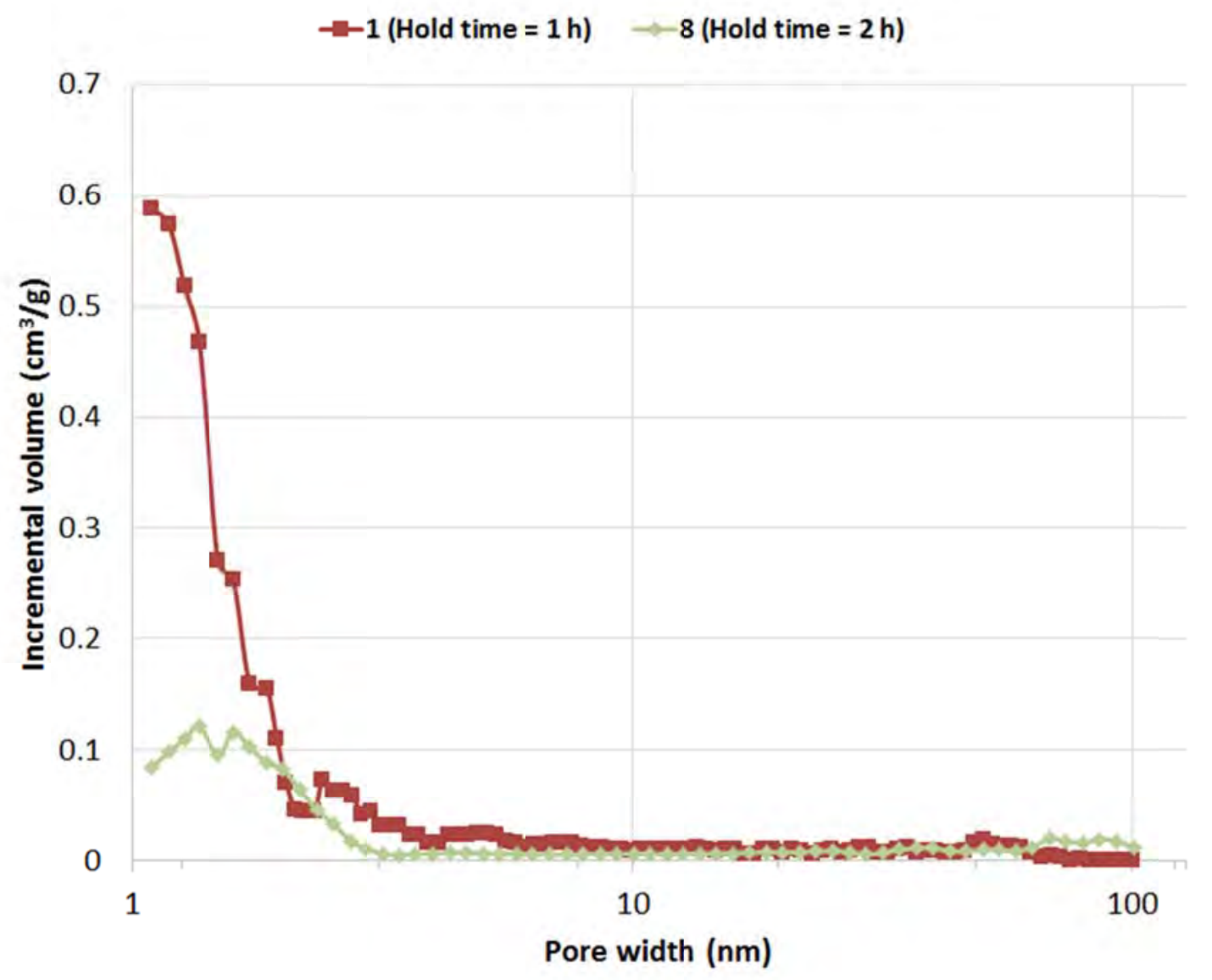

Figure 4. Micropore and mesopore size distribution of activated carbons (hold time)

For the analysis of the influence of hold time in the activation process, Figure 4 shows the effect of increasing it from 1 to 2 hours for the case of activation with carbon dioxide (cases 1 and 8). The microporosity of activated carbon produced at 2 hours decreases in relation to the one obtained at 1 hour. Increasing the activation time at constant temperature $\left(800{ }^{\circ} \mathrm{C}\right)$ has led to a 
decrease in the BET surface area (from 789 to $160 \mathrm{~m}^{2} / \mathrm{g}$ ), total pore volume (from 0.3495 to $0.0849 \mathrm{~cm}^{3} / \mathrm{g}$ ) and micropores volume (from 0.3268 to $0.0657 \mathrm{~cm}^{3} / \mathrm{g}$ ), due to the destruction of the microporosity by enlargement and collapse. It can be then concluded that the destruction of micropores exceeded that of new pores formation. For the case of steam activation, considering that after the first stage of the activation process the char does not continue developing new micropores, the effect on the reduction of the microporous structure is even greater.

Finally, the effect of activating agent gas flow rate was analyzed. In this case, Figure 5 shows the result of reduction from 4000 to $2500 \mathrm{~cm}^{3} / \mathrm{min}$ for the case of activation with steam (cases 10 and 12). The adsorption isotherms in Figure 2 and the pore size distributions shown in Figure 5 are practically identical for both cases. Considering that the flow rate in case 10 is almost double that of case 12, the small differences observed in the results which also show a minimum increase in the BET surface area, total volume and micropore volume with the flow rate, are not significant to suggest a relevant influence of this parameter, since differences might be also attributable to the heterogeneity of the raw barley straw samples.

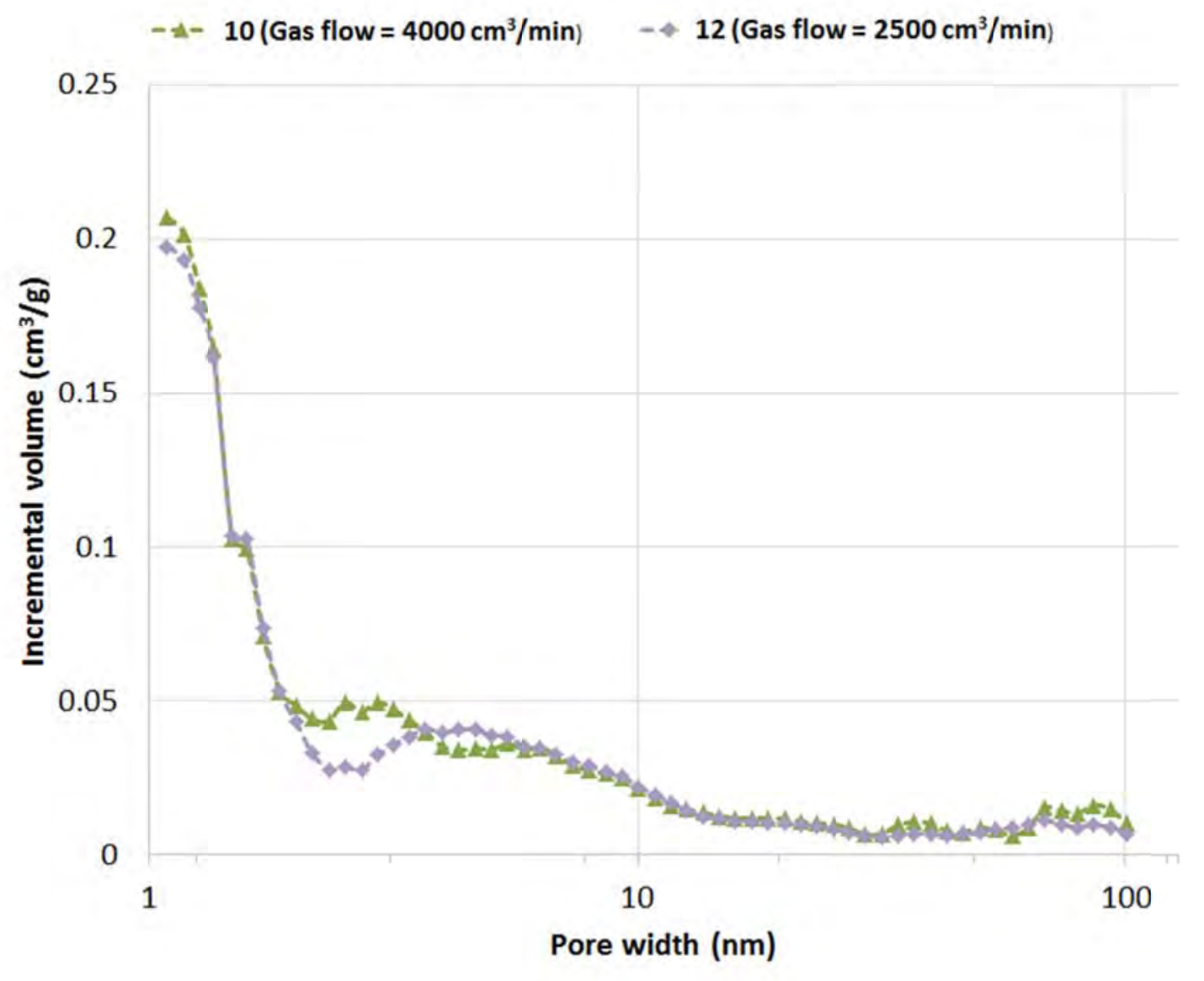

Figure 5. Micropore and mesopore size distribution of activated carbons (gas flow rate) 


\subsection{SEM Analysis}

In order to examine the surface morphology, figure 6 shows SEM micrographs of activated carbon produced under the following conditions: carbon dioxide activation at $700{ }^{\circ} \mathrm{C}(\mathrm{a}), 800{ }^{\circ} \mathrm{C}$ (b) and $900{ }^{\circ} \mathrm{C}$ (c), and steam activation at $600{ }^{\circ} \mathrm{C}(\mathrm{d}), 700{ }^{\circ} \mathrm{C}(\mathrm{e})$ and $800{ }^{\circ} \mathrm{C}(\mathbb{f})$. Examination of the micrographs corresponding to the activated carbon obtained under optimum conditions for carbon dioxide activation at $800{ }^{\circ} \mathrm{C}$ (Figure 6.b) and steam activation at $700{ }^{\circ} \mathrm{C}$ (Figure 6.e), shows a considerable difference in the porosity developed by both samples. While the former exhibits a great number of macro, meso and micropores distributed over the entire surface, in the latter there is only evidence of the existence of macro and mesopores.
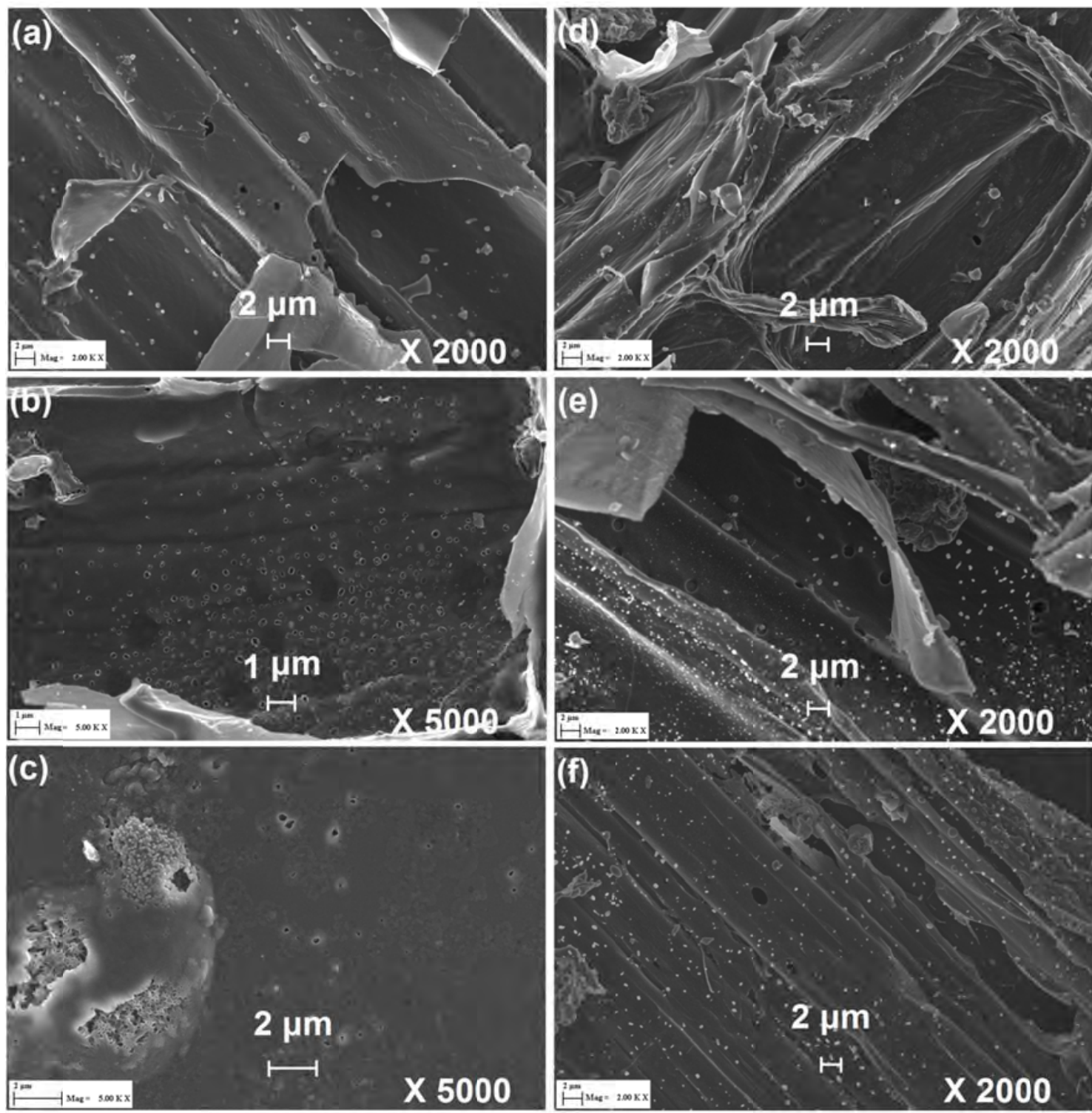

Figure 6. Scanning electron micrographs of activated carbon by $\mathrm{CO}_{2}$ activation at $700^{\circ} \mathrm{C}($ a), $800{ }^{\circ} \mathrm{C}\left(\right.$ b) and $900{ }^{\circ} \mathrm{C}(\mathrm{c})$, and by $\mathrm{H}_{2} \mathrm{O}$ activation at $600{ }^{\circ} \mathrm{C}(\mathrm{d}), 700^{\circ} \mathrm{C}(\mathrm{e})$ and $800{ }^{\circ} \mathrm{C}(f)$ 
Magnified micrographs (X100000 and X50000) of these surface regions are shown in Figure 7. Besides the aforementioned difference in pore size, the contrast between the soft and rough surfaces obtained by carbon dioxide and steam activation respectively can be clearly appreciated. This difference is caused by a greater reactivity in the case of steam activation, and by the formation of small spherical structures composed mainly of Si, O and K (see spectrums 1 and 3 in Figure 8.b), which can be associated with coalesced ash and sintered particles [14] [17].
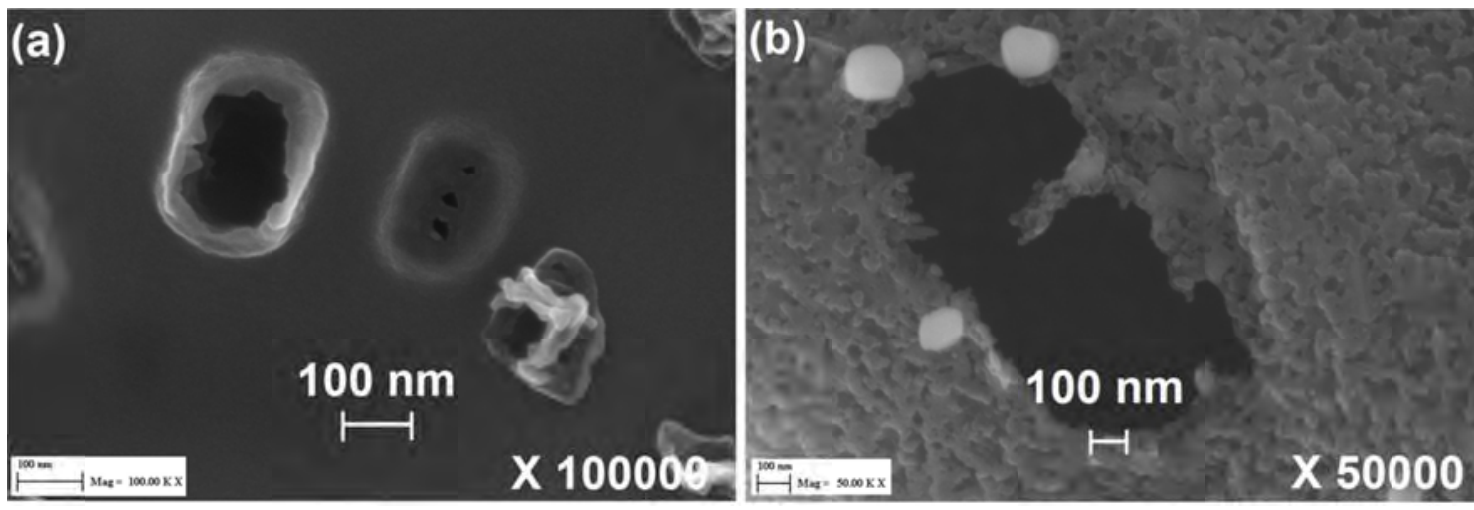

Figure 7. Scanning electron micrographs of activated carbon by $\mathrm{CO}_{2}$ activation at $800{ }^{\circ} \mathrm{C}$ (a) and by $\mathrm{H}_{2} \mathrm{O}$ activation at $700{ }^{\circ} \mathrm{C}($ b).

The effect of activation temperature on the developed microporosity, discussed in section 3.1.2, is confirmed by comparing the micrographs of Figure 6 at different temperatures: a - b - c for carbon dioxide and $\mathrm{d}$ - e - $\mathrm{f}$ for steam. In the case of carbon dioxide, the increase in porosity is clear when the temperature increases from 700 to $800{ }^{\circ} \mathrm{C}$ (Figures 6.a and 6.b respectively). However, as it was previously indicated, the microporous structure disappears at $900{ }^{\circ} \mathrm{C}$ (Figure 6.c) due to the formation of the melting phase which fills and blocks the previously developed pores. Energy dispersive X-ray spectrometry measurements at different regions of the sample confirm these results, since they show a rich presence of $\mathrm{Si}, \mathrm{O}, \mathrm{K}, \mathrm{Ca}$ and $\mathrm{Mg}$ on the surface (see spectrum in Figure 8.a), all of which are primary contributors to the formation of low melting point eutectics.

Finally, in the case of activation with steam, the increase in porosity is clear when temperature increases from $600{ }^{\circ} \mathrm{C}$ to $700{ }^{\circ} \mathrm{C}$ (Figures 6.d and 6.e respectively). However, from a morphological point of view no differences were observed between the micrographs obtained at $700{ }^{\circ} \mathrm{C}$ and $800{ }^{\circ} \mathrm{C}$. This result is consistent with the physisorption results presented in section 3.1, since both samples have a similar porosity. 

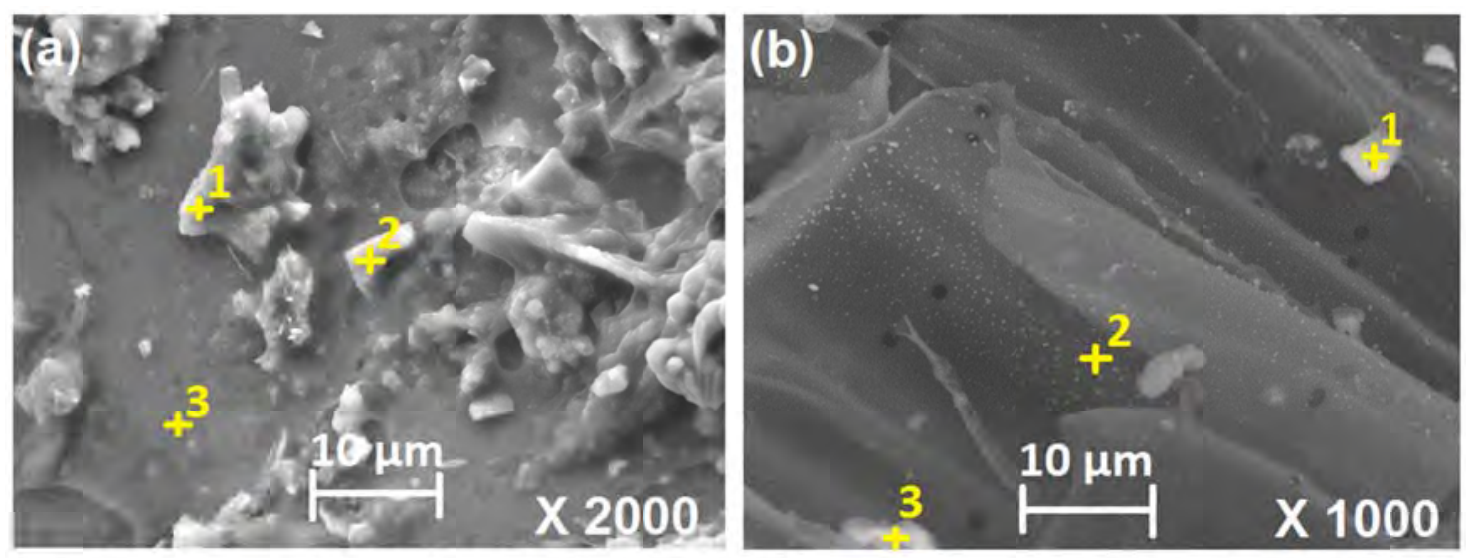

\begin{tabular}{|l|c|c|c|c|c|c|c|c|c|c|}
\hline $\begin{array}{l}\mathbf{C O}_{2}(\mathbf{9 0 0} \\
\text { Figure 8.a }\end{array}$ & C & O & Na & Mg & Al & Si & P & Cl & K & Ca \\
\hline spectrum 1 & 30.90 & 44.75 & & 2.24 & 1.02 & 6.18 & 1.56 & 0.12 & 8.65 & 4.59 \\
\hline spectrum 2 & 28.07 & 43.42 & 0.18 & 1.81 & 3.27 & 8.21 & 1.21 & & 8.77 & 5.06 \\
\hline spectrum 3 $_{\mathbf{H}_{2} \mathbf{O}\left(\mathbf{7 0 0}^{\circ} \mathbf{C}\right)}$ & 13.48 & 37.97 & 0.31 & 1.00 & & 25.69 & 0.54 & & 16.37 & 4.64 \\
\hline Figure 8.b $^{\text {spectrum 1 }}$ & $\mathbf{C}$ & $\mathbf{O}$ & $\mathbf{N a}$ & $\mathbf{M g}$ & $\mathbf{A l}$ & $\mathbf{S i}$ & $\mathbf{P}$ & $\mathbf{C l}$ & $\mathbf{K}$ & $\mathbf{C a}$ \\
\hline spectrum 2 $^{\text {spectrum 3 }}$ & 30.83 & 36.43 & & 0.17 & 0.34 & 27.48 & & 0.23 & 4.52 & \\
\hline
\end{tabular}

Figure 8. Energy dispersive X-ray spectrometry of activated carbon (\% wt.) by $\mathrm{CO}_{2}$ activation at $900{ }^{\circ} \mathrm{C}$ (a) and by $\mathrm{H}_{2} \mathrm{O}$ activation at $700{ }^{\circ} \mathrm{C}(\mathrm{b})$.

\subsection{FTIR analysis}

Besides its physical properties, some chemical properties of activated carbon such as hydrophobicity, polarity, cation-exchange capacity, acidic or basic character, electrostatic charge, etc., are also characterized by the presence of different functional groups on its surface. These properties can have a great effect on its adsorption capacity of different pollutants and therefore on its suitability for its final use.

Figure 9 shows the FTIR spectra of activated carbon by carbon dioxide activation at $800^{\circ} \mathrm{C}$ and steam activation at $700^{\circ} \mathrm{C}$, corresponding to cases 1 and 10 , in which the microporosity of the final materials was maximized. The spectrum under carbon dioxide activation shows bands in the region $2324-1982 \mathrm{~cm}^{-1}$ attributed to $\mathrm{C}=\mathrm{O}$ stretching in aldehydes, ketones and esters [23]; a band at $1744 \mathrm{~cm}^{-1}$ assigned to carboxylic groups and lactones; bands at 1456i and $1377 \mathrm{~cm}^{-1}$ by the presence of phenolic groups; a band at $995 \mathrm{~cm}^{-1}$ corresponding to C-O stretching vibrations and bands in the region 700-900 $\mathrm{cm}^{-1}$ representing aromatic C-H groups [13]. The spectrum under steam activation shows similar bands but with a higher intensity in the $1300-1500 \mathrm{~cm}^{-1}$ region assigned to phenolic groups and in the region $1900-2400 \mathrm{~cm}^{-1}$ attributed to $\mathrm{C}=\mathrm{O}$ stretching. In both cases, the absence of bands in the range $3000-3500 \mathrm{~cm}^{-11}$ corresponding to the O-H stretching of the hydroxyl group and in the bands at 2920 and $2850 \mathrm{~cm}^{-1}$ corresponding 
to aliphatic $\mathrm{C}-\mathrm{H}$ groups suggests the elimination of the $\mathrm{OH}$ groups and an increase in the aromaticity of the char during the activation process.

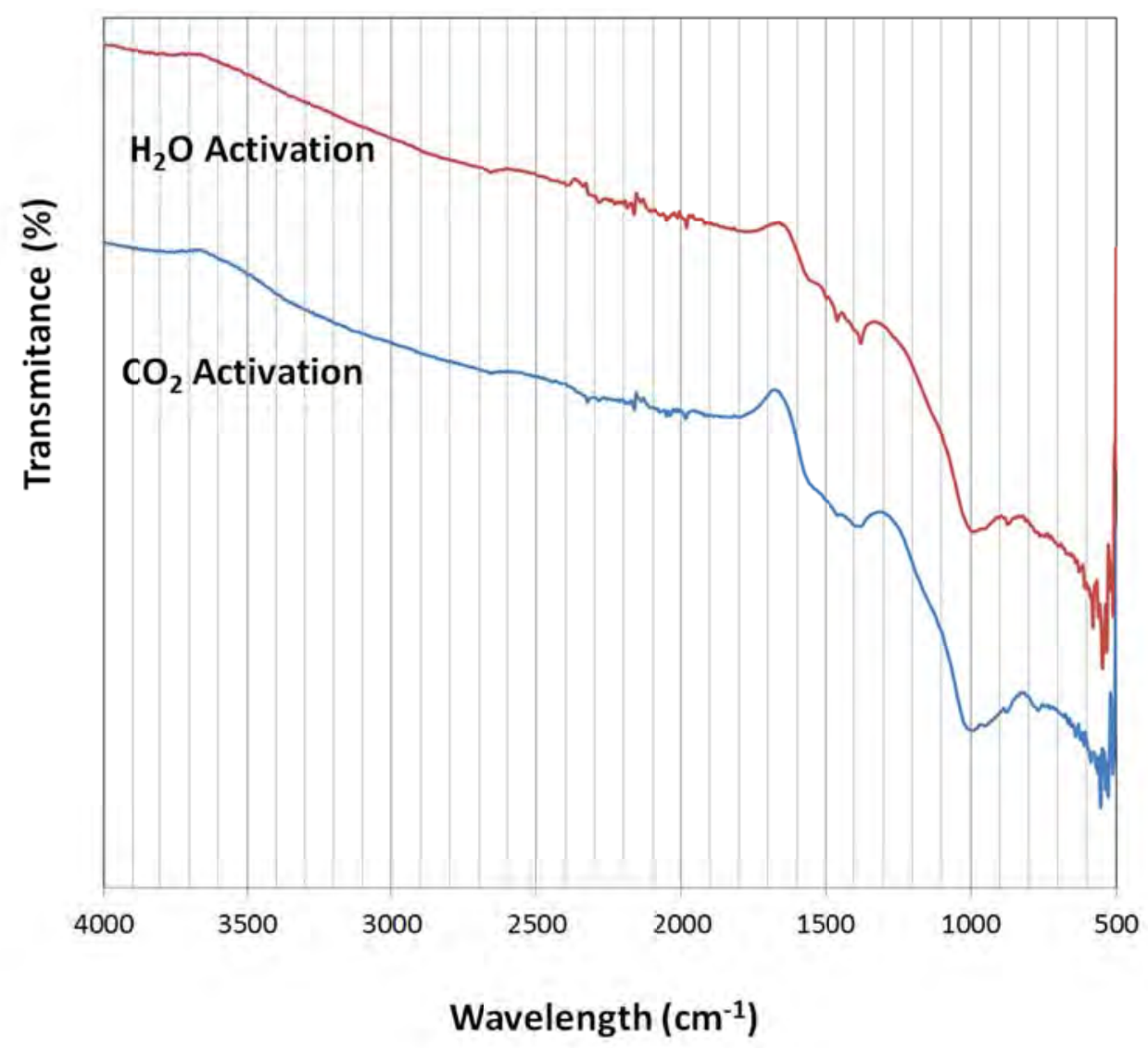

Figure 9. ATR-FTIR spectra of activated carbon by $\mathrm{CO}_{2}$ activation at $800{ }^{\circ} \mathrm{C}$ and $\mathrm{H}_{2} \mathrm{O}$ activation at $700^{\circ} \mathrm{C}$.

\subsection{Chemical composition}

Table 6 shows the elemental composition for raw barley straw and activated carbons obtained under carbon dioxide activation at $800{ }^{\circ} \mathrm{C}$ (case 1) and steam activation at $700{ }^{\circ} \mathrm{C}$ (case 10). Carbon content increased from $45.40 \%$ to $51.68 \%$ in the case of carbon dioxide activation and to $69.20 \%$ for steam activation, because of the volatile release and heterogeneous reforming reactions at high temperature. It can also be observed that the $\mathrm{H} / \mathrm{C}$ and $\mathrm{O} / \mathrm{C}$ atomic ratios of activated carbons are lower than those of the raw biomass. While the $\mathrm{H} / \mathrm{C}$ ratio is very similar in both cases, the $\mathrm{O} / \mathrm{C}$ ratio is lower for the case of steam activation. This decrease in both atomic $\mathrm{H} / \mathrm{C}$ and $\mathrm{O} / \mathrm{C}$ ratios of activated carbon can be attributed to the loss of $\mathrm{OH}$ groups caused by the dehydration and dehydrogenation reactions, the breaking of weak hydrogen bonds within the char structure, and the loss of volatile organic products [35]. Said decrease is also indicative of a high degree of aromaticity which means that activated carbons mostly consist of fixed carbon aromatic rings. This result is in accordance to the FTIR spectra results (section 3.3), which also 
suggest an elimination of $\mathrm{OH}$ groups and an increase in the aromaticity of the char during the activation process. Similar values are reported in the literature for activated carbons and biomass steam gasification chars [13, 35].

\begin{tabular}{|c|c|c|c|c|c|c|c|}
\hline & C & $\mathbf{H}$ & $\mathbf{N}$ & $\mathbf{S}$ & $\mathbf{O}$ & $\mathrm{H} / \mathrm{C}$ & $\mathrm{O} / \mathrm{C}$ \\
\hline Raw biomass & 0.4540 & 0.0610 & 0.0070 & 0.0007 & 0.4192 & 1.615 & 0.699 \\
\hline Test $1\left(\mathrm{CO}_{2}\right)$ & 0.5188 & 0.0050 & 0.0198 & 0.0017 & 0.1029 & 0.114 & 0.149 \\
\hline Test $10\left(\mathrm{H}_{2} \mathrm{O}\right)$ & 0.6920 & 0.0077 & 0.0067 & 0.0000 & 0.0396 & 0.133 & 0.043 \\
\hline
\end{tabular}

Table 6. Ultimate analysis (dry basis) and $\mathrm{H} / \mathrm{C}$ and $\mathrm{O} / \mathrm{C}$ atomic ratio for raw biomass and activated carbons by $\mathrm{CO}_{2}$ activation at $800{ }^{\circ} \mathrm{C}$ and $\mathrm{H}_{2} \mathrm{O}$ activation at $700{ }^{\circ} \mathrm{C}$.

\begin{tabular}{|c|c|c|c|}
\hline Element & Test $\mathbf{1}\left(\mathbf{C O}_{\mathbf{2}}\right) \mathbf{~ m g} / \mathbf{g}$ & Test $\mathbf{1 0}\left(\mathbf{H}_{\mathbf{2}} \mathbf{O}\right) \mathbf{~} \mathbf{g} / \mathbf{g}$ & Raw $\mathbf{( m g} / \mathbf{g})$ \\
\hline $\mathbf{A l}$ & 2.121 & 1.381 & 0.43 \\
\hline $\mathbf{C a}$ & 21.65 & 17.06 & 3.621 \\
\hline $\mathbf{C u}$ & 0.023 & - & 0.01 \\
\hline $\mathbf{F e}$ & 1.021 & 1.079 & 0.17 \\
\hline $\mathbf{K}$ & 75.05 & 57.35 & 9.223 \\
\hline $\mathbf{M g}$ & 6.313 & 4.642 & 0.942 \\
\hline $\mathbf{M n}$ & 0.164 & 0.142 & 0.03 \\
\hline $\mathbf{N a}$ & 1.021 & 0.782 & 0.241 \\
\hline $\mathbf{P}$ & 3.697 & 2.624 & 0.699 \\
\hline $\mathbf{S}$ & 1.788 & 0.768 & 0.756 \\
\hline $\mathbf{T i}$ & 0.109 & 0.084 & 0.016 \\
\hline $\mathbf{Z n}$ & 0.081 & 0.046 & 0.011 \\
\hline
\end{tabular}

Table 7. Mineral content of raw biomass and activated carbons by $\mathrm{CO}_{2}$ activation at $800^{\circ} \mathrm{C}$ and $\mathrm{H}_{2} \mathrm{O}$ activation at $700^{\circ} \mathrm{C}$.

Finally, Table 7 summarizes the inorganic elements in raw biomass and activated carbons determined by ICP-OES analysis. Due to the thermal process, the concentration of inorganic elements on activated carbons is higher than that in raw biomass. Moreover, when comparing the mineral contents of activated carbons, it is clear that the concentrations of all elements corresponding to carbon dioxide activation are higher than those of steam activation, due to the lower carbon content and higher ash content of the final activated carbon produced under $\mathrm{CO}_{2}$ activation at $800{ }^{\circ} \mathrm{C}$. By normalizing these values per gram of mineral matter, similar concentrations are obtained in both cases, although lower than those of the raw because of the release of species during the devolatilization process. The major elements in activated carbons ( $>0.1 \mathrm{wt} \%$ ) were $\mathrm{K}, \mathrm{Ca}, \mathrm{Mg}, \mathrm{P}, \mathrm{S}, \mathrm{Fe}$ and $\mathrm{Al}$, while the minor elements $(<0.1 \mathrm{wt} \%)$ included $\mathrm{Na}, \mathrm{Mn}, \mathrm{Cu}, \mathrm{Zn}$ and other heavy metals. Among major minerals, $\mathrm{K}$ is the most abundant element. Its concentration in the case of activation with carbon dioxide is $30 \%$ higher than in the case with steam, and $714 \%$ with respect to the raw material. There is also a significant presence 
of $\mathrm{Ca}, \mathrm{Mg}$ and P. For these elements, the increase of their concentration for activation with carbon dioxide with respect to the case with steam is $27 \%, 36 \%$ and $41 \%$ respectively.

\section{Conclusions}

In this study, the production of activated carbon from barley straw using the physical activation method with two different activating agents, pure carbon dioxide and pure steam, has been investigated. The maximum BET surface area and micropore volume reached by carbon dioxide activation were $789 \mathrm{~m}^{2} / \mathrm{g}$ and $0.3268 \mathrm{~cm}^{3} / \mathrm{g}$, while by steam activation were $552 \mathrm{~m}^{2} / \mathrm{g}$ and $0.2304 \mathrm{~cm}^{3} / \mathrm{g}$. This represents respectively an increase of more than $43 \%$ and $42 \%$ for the case of activation with carbon dioxide under the conditions analyzed in this study. The activated carbons obtained by carbon dioxide activation also presented a well-developed microporosity. In the case of steam activation, the microporosity of the material was also predominant but with a lower degree of development than that of the carbon dioxide activation due to a higher reactivity of steam at high temperatures which gives rise to a pore wide enlarging and an increase in mesoporosity at the expense of microporosity. Activated carbons shown a high degree of aromaticity with the presence of oxygen functional groups (carboxylates, lactones and phenols) on its surface. Major elements in activated carbons ( $>0.1$ wt\%) are $\mathrm{K}, \mathrm{Ca}, \mathrm{Mg}, \mathrm{P}, \mathrm{S}, \mathrm{Fe}$ and $\mathrm{Al}$, while minor elements ( $<0.1 \mathrm{wt} \%)$ included $\mathrm{Na}, \mathrm{Mn}, \mathrm{Cu}$, Zn and other heavy metals Moreover, carbon dioxide activation achieved 30-50\% higher concentrations of inorganic elements with respect to steam activation. .

The influence of the different operating variables at each stage of the process, carbonization and activation, has also been investigated with the aim to maximize the BET surface area and microporosity of the final product. Final temperature and heating rate have been shown to be the most relevant factors during the carbonization stage. Initially, an increase of any of these variables resulted in an increase of the porous structure. However, a maximum was reached which the appearance of melting and sintering phenomena that reversed this tendency. On the other hand, pyrolysis hold time and gas flow rate has not been identified as relevant factors in the carbonization process under the conditions analyzed. Optimal conditions of the carbonization stage were obtained at $500{ }^{\circ} \mathrm{C}$, a heating rate of $10{ }^{\circ} \mathrm{C} / \mathrm{min}$, a hold time of 1 hour and a nitrogen gas flow rate of $2500 \mathrm{~cm}^{3} / \mathrm{min}$. Regarding the activation stage with carbon dioxide, both BET surface area and the total volume of pores and micropores increased remarkably with temperature from 700 to $800{ }^{\circ} \mathrm{C}$. However, at $900{ }^{\circ} \mathrm{C}$ low melting temperature silicates started to appear, and this melting phase filled and blocked the existing pores. In the case of steam activation, there was also an increase in the development of the microporous structure with temperature from $600{ }^{\circ} \mathrm{C}$ to $700{ }^{\circ} \mathrm{C}$. At $800{ }^{\circ} \mathrm{C}$, a decrease in the BET surface area $(-3 \%)$ and in the micropore volume $(-5.4 \%)$ was obtained, but an increase in the total 
volume of pores (9.6\%) due to mesopore widening. Hold time has also a great effect in the activation process. Under the conditions analyzed, increasing hold time from 1 to $2 \mathrm{~h}$ led to the destruction of most of the microporosity by enlargement and collapse. Finally, gas flow rate variations did not seem to have a significant effect on the process. Thus, optimal conditions of the activation stage were obtained at $800{ }^{\circ} \mathrm{C}$ and a hold time of $1 \mathrm{~h}$ in the case of activation with carbon dioxide and at $700^{\circ} \mathrm{C}$ and a hold time of $1 \mathrm{~h}$ in the case of activation with steam.

The activated carbon produced under optimal conditions demonstrates the potentiality of barley straw as a low cost precursor material for the production of activated carbon, showing a surface area and microporosity similar to that of commercial activated carbons and those obtained from other residual biomass precursors.

\section{Acknowledgements}

The work presented in this paper has been funded by the Spanish Ministry of Economy and Competitiveness in RETOS-COLABORACIÓN program (Project RTC-2015-3411-5) cofinanced by the European Union with ERDF. The authors also gratefully acknowledge Inmaculada Ramos for her collaboration during the experimental test campaign, and the Servicios de Apoyo a la Investigación (University of Zaragoza), the Instituto de Carboquímica (ICB), the CEDER-CIEMAT and the Instituto de Nanociencia de Aragón (INA) for their assistance in the physical and chemical characterization of the raw materials and activated carbons.

\section{References}

[1]. World activated Carbon. Industry study with forecast 2018-2023. The Freedonia group (2014).

[2]. M.G. Plaza, A.S. González, J.J. Pis, F. Rubiera, C. Pevida, Production of microporous biochars by single-step oxidation: Effect of activation conditions on $\mathrm{CO}_{2}$ capture, Applied Energy 114 (2014) 551-562.

[3]. X.F. Tan, S.B. Liu, Y.G. Liu, Y.L. Gu, G.M. Zeng, X.J. Hu, X. Wang, S.H. Liu, L.H. Jiang, Biochar as potential sustainable precursors for activated carbon production: multiple applications in environmental protection and energy storage, Bioresource Technology 227 (2017) 359-372.

[4]. R. Farma, M. Deraman, A. Awitdrus, L.A. Talib, E. Taer, N.H. Basri, J.G. Manjunatha, M.M. Ishak, B.N.M. Dollah, S.A. Hashmi, Preparation of highly porous binderless activated carbon electrodes fron fibres of oil plam empty fruit bunches for application in supercapacitors, Bioresource Technology 132 (2013) 254-261. 
[5]. K.Y. Chan, L.V. Zwieten, I. Meszaros, A. Downie, S. Joseph, Agronomic values of greenwaste biochar as a soil amendment, Journal of Soil Research 45 (2007) 629-634.

[6]. K.A. Spokas, J.M. Novak, R.T. Venterea, Biochar's role as an alternative N-fertilizer: ammonia capture, Plant and Soil 350 (2012) 35-42.

[7]. O.A. Knowles, B.H. Robinson, A. Contangelo, L. Clucas, Biochar for the mitigation of nitrate leaching from soil amended with biosolids, Science of the total Environment 409 (2011) 3206-3210.

[8]. M. Plaza Carbón activado evaluación de nuevos precursores y del proceso de activación con dióxido de carbono. Ph.D Thesis, University of Alicante (2015).

[9]. Y.J. Zhang, Z.J. Xing, Z.K. Duan, M. Li, Y.Wang, Effects of steam activation on the pore structure and surface chemistry of activated carbon derived from bamboo waste, Applied Surface Science 315 (2014) 279-286.

[10]. M. Molina-Sabio, M.T. González, F. Rodriguez-Reinoso, A. Sepúlveda-Escribano, Effect of steam and carbon dioxide activation in the micropore size distribution of activated carbon, Carbon 34 (1996) 505-509.

[11]. Ch.F. Chang, Ch.Y. Chang, W.T. Tsai, Effects of burn-off and activation temperature on preparation of activated carbon from corn cob agrowaste by $\mathrm{CO}_{2}$ and steam, Journal of Colloid and Interface Science 232 (2000) 45-49.

[12]. A. Aworn, P. Thiravetyan, W. Nkbanpote, Preparation and characteristics of agricultural waste activated carbon by physical activation having micro and mesopores, Journal of Analytical and Applied Pyrolysis 82 (2008) 279 - 285.

[13]. N. Rambabu, B.V.S.K. Rao, V.R. Surisetty, U. Das, A.K. Dalai, Production, characterization and evaluation of activated carbons from de-oiled canola meal for environmental applications, Industrial Crops and Products 65 (2015) 572 - 581.

[14]. M.B. Ahmed, J.L. Shou, H.H. Ngo, W. Guo, M. Chen, Progress in the preparation and application of modified biochar for improved contaminant removal from water and wasterwater, Bioresources Technology 214 (2016) 836-851.

[15]. A.U. Rajapaksha, S.S. Chen, D.C.W. Tsang, M. Zhang, M. Vinthanage, S. Mandal, B. Gao, N.S. Bolan, Y.S. Ok, Engineered/designer biochar for contaminant removal/inmobilization from soil and water: potential and implication of biochar modification, Chemosphere 148 (2016) 276-291.

[16]. X.F. Tan, Y.G. Liu, Y.L. Gu, Y. Xu, G.M. Zeng, X.J. Hu, S.B. Liu, X. Wang, S.M. Liu, J. Li, Biochar-based nano-composites for the decontaminaton of wastewater: a review, Bioresource Technology 212 (2016) 318-333.

[17]. A. Marcilla, S. García-García, M. Asensio, J.A. Conesa, Influence of thermal treatment regime on the density and reactivity of activated carbons from almond shells, Carbon 38 (2000) 429 - 440. 
[18]. D. Savova, E. Apak, E. Ekinci, F. Yardim, N. Petrov, T. Budinova, M. Razvigorova, V. Minkova, Biomass conversion to carbon absorbents and gas, Biomass and Bioenergy 21 (2001) $133-142$.

[19]. A.N.A. El-Hendawy, S.E. Samra, B.S. Girgis, Adsorption characteristics of activated carbons obtained from corncobs, Colloids and Surfaces A: Physicochemical and Engineering Aspects 180 (2001) 209 - 221.

[20]. B. Girgis, S.S. Yunis, A.M. Soliman, Characteristics of activated carbon from peanut hulls in relation to conditions of preparation, Materials Letters 57 (2002) 164 - 172.

[21]. M. Fan, W. Marshall, R.C. Brown, Steam activation of chars produced from oat hulls and corn stover, Bioresource Technology 93 (2004) 103 - 107.

[22]. T. Zhang, Walawender W.P., Fan L.T., Fan M., Daugaard D., Brown R.C. Preparation of activated carbon from forest and agricultural residues through $\mathrm{CO}_{2}$ activation, Chemical Engineering Journal 105 (2004) 53 - 59.

[23]. C. Bouchelta, M.S. Medjram, O. Bertrand, J.P. Bellat, Preparation and characterization of activated carbon from date stones by physical activation with steam, Journal of Analytical and Applied Pyrolysis 82 (2008) 70 - 77.

[24]. C. Okutucu, G. Duman, S. Ucar, I. Yasa, J. Yanik, Production of fungicidal oil and activated carbon from pistachio shell, Journal of Analytical and Applied Pyrolysis 91 (2011) $140-146$.

[25]. H. Demiral, I. Demiral, B. Karabacakoglu, F. Tümsek, Production of activated carbon from olive bagasse by physical activation,Chemical Engineering Research and Design 89 (2011) $206-213$.

[26]. Ö. Sahin, C. Saka, Preparation and characterization of activated carbon from acorn shell by physical activation with $\mathrm{H}_{2} \mathrm{O}-\mathrm{CO}_{2}$ in two-step pretreatment, Bioresource Technology 136 (2013) $163-168$.

[27]. B. Cagnon, X. Py, A. Guillot, F. Stoeckli, The effect of the carbonization/activation procedure on the microporous texture of the subsequent chars and active carbons, Microporous and Mesoporous materials 57 (2003) 273-282.

[28]. A.Ch. Lua, T. Yang, J. Guo, Effects of pyrolysis conditions on the properties of activated carbons prepared from pistachio-nut shells, Journal of Analytical Applied Pyrolysis 72 (2004) $279-287$.

[29]. A.Ch. Lua, F.Y. La, J. Guo, Influence of pyrolysis conditions on pore development of oilpalm-shell activated carbons, Journal of Analytical and Applied Pyrolysis 76 (2006) 96102.

[30]. Ch. Bouchelta, M.S. Medjram, M. Zoubida, F.A. Chekkat, N. Ramdane, J.P. Bellat, Effects of pyrolysis conditions on the porous structure development of date pits activated carbon, Journal of Analytical and Applied Pyrolysis 94 (2012) 215-222. 
[31]. M. Loredo-Cancino, E. Soto-Regalado, F.J. Cerino-Córdoba, R.B. García-Reyes, A.M. García-León, M.T. Garza-González, Determining optimal conditions to produce activated carbon from barley husks using single or dual optimization, Journal of Environmental Management 125 (2013) $117-125$.

[32]. Agricultural productions: Cereals. Ministry of Agriculture, Fishing, Food and Environment. Government of Spain (2017). (http://www.mapama.gob.es/en/; visited 23/1/2018).

[33]. Good Practice Guidance and Uncertainty Management in National Greenhouse Gas Inventories. Chapter 4: Agriculture. International Panel for Climate Change (2001).

[34]. IUPAC, Recommendations for the characterization of porous solids, Pure and Applied Chemistry 66 (1994) 1739-1758.

[35]. S. You, Y.S. Ok, S.S. Chen, D.C.W. Tsang, E.E. Kwon, J. Lee, Ch.H. Wang, A critical review on sustainable biochar system through gasification: Energy and environmental applications, Bioresource Technology 246 (2017) 242-253. 